Draft of paper to appear in the Blackwell Companion to Experimental Philosophy ed. by Wesley Buckwalter \& Justin Sytsma

\title{
Experimental Philosophy and the Philosophical Tradition
}

\author{
Stephen Stich \\ Rutgers University \\ Kevin Tobia \\ Yale University
}

\section{Introduction}

The term "experimental philosophy" has no standard or widely agreed upon definition, and recent writers have proposed very different accounts of how the term should be used (Knobe and Nichols 2008; Alexander 2012; Rose and Danks 2013; Alfano and Loeb, 2014; Knobe this volume). On the usage we prefer, the term has a broad extension and very fuzzy boundaries: experimental philosophy is empirical work undertaken with the goal of contributing to a philosophical debate, though of course that may not be the only goal. Sometimes people doing experimental philosophy conduct experiments, but sometimes they don't. Philosophically motivated ethnography like Richard Brandt's pioneering study of Hopi ethics (Brandt 1954) and John Ladd's study of the moral code of the Navaho (Ladd 1957) certainly count as experimental philosophy, on our interpretation of the term. Indeed, we think that Brandt and Ladd have a good claim to being the first important contributors to contemporary experimental philosophy. Many experimental philosophers are philosophers by training and professional affiliation, but some of the best work in experimental philosophy has been done by people who do not have advanced degrees in philosophy and do not teach in philosophy departments. The work on altruism by the social psychologist Daniel Batson is, in our view, one of the very best examples of experimental philosophy to date (Batson 1991; 2011).

During the last decade, the term "experimental philosophy" has often been used in a much more restricted way. On that more restricted interpretation, which we will adopt for the remainder of this chapter, experimental philosophy is the empirical investigation of philosophical intuitions, the factors that affect them, and the psychological and neurological mechanisms that underlie them. This characterization of experimental philosophy immediately raises a pair of questions:

1. What are philosophical intuitions?

2. Why do experimental philosophers want to study them using the methods of empirical science?

Our goal in the remainder of this chapter will be to explore answers to these questions and explain how these answers link experimental philosophy to the philosophical tradition. 


\section{What Are Philosophical Intuitions?}

We'll begin with the first question, around which a lively controversy has erupted, with different philosophers defending quite different accounts (Bealer 1998; Goldman 2007; Ludwig 2007; Pust 2000; Sosa 2007a; Williamson 2004; for a useful overview, see Alexander 2012). We think that the best way to approach this question is to focus on paradigm cases - uncontroversial examples of the appeal to intuitions in philosophical argument. ${ }^{1}$ Throughout the history of Western philosophy, episodes like the following have played an important role in philosophical argument. A philosopher describes a situation, sometimes real but more often imaginary, and asks whether some of the people or objects or events in the situation described have some philosophically interesting property or relation:

- Is the action described morally wrong?

- Does the person described know that she will not win the lottery?

- When the speaker in the story uses the word 'water' does the word refer to $\mathrm{H}_{2} \mathrm{O}$ ?

- Does the "Chinese Room" exhibit real intentionality?

When things go well, both the philosopher and her audience will agree on an answer, with little or no conscious reflection, and they will take the answer to be obvious. The answer will then be used as evidence for or against some philosophical thesis. The mental states that underlie episodes of this sort are paradigm cases of philosophical intuitions.

Examples of this strategy of argument can be found in the writings of many historically important philosophers. Here is a well-known passage from Plato's Republic in which Socrates uses the strategy in a conversation about the nature of justice.

Well said, Cephalus, I replied: but as concerning justice, what is it? - to speak the truth and to pay your debts - no more than this? And even to this are there not exceptions? Suppose a friend when in his right mind has deposited arms with me and he asks for them when he is not in his right mind, ought I to give them back to him? No one would say that I ought or that I should be right in doing so, any more than they would say that I ought always to speak the truth to one who is in his condition.

You are quite right, he replied.

But then, I said, speaking the truth and paying your debts is not a correct definition of justice.

Quite correct, Socrates. (Plato, 1892, I, 131, 595; italics \& boldface added)

In the italicized sentence, Socrates sets out the imaginary situation and poses a question about justice. In the following sentence (in boldface), he reports his own intuition and confidently asserts what contemporary philosophers typically assume, viz. that everyone 
who was confronted with the question would share his intuition. Cephalus reports the same intuition and agrees that the intuition would be shared by everyone. Then Socrates argues that the intuition shows that the account of justice that Cephalus has offered is mistaken.

Lots of examples like this can be found in more recent philosophy; they are particularly abundant in many areas of contemporary "analytic" philosophy. Here is a very brief catalog:

(1) In metaphysics, debates about personal identity still invoke intuitions about Locke's famous example of the prince and the cobbler, along with a wide variety of more recent cases in which brains are transplanted, memories and whole bodies are duplicated, and people use Star Trek teletransporters.

(2) In ethics, intuitions about wayward trollies, organ harvesting, Roman circuses, inquiring murderers, children drowning in bathtubs, violinists whose survival requires being connected to someone else for nine months, and a host of other cases fill the literature.

(3) In discussions of free will, philosophers often invoke intuitions about people locked in prison cells, people with brain implants controlled by evil scientists, people who dislike their own desires and a variety of other cases.

(4) In epistemology, appeal to intuitions about lottery cases, fake barn cases, stakes cases, and a seemingly endless variety of Gettier cases abound.

(5) In the philosophy of language, philosophers rely on intuitions about sorites cases, Twin Earth cases, Gödel cases and arthritis cases, among many others.

(6) Elsewhere in the philosophy of language, when working out the semantics of philosophically important expressions, intuitions about what a sentence entails (or does not entail) are crucial. For example, Donald Davidson (following Anthony Kenny) famously argued that we have the intuition that (i) "Jones buttered the toast in the bathroom with a knife at midnight" entails (ii) "Jones buttered the toast," and that poses a problem for philosophers who would analyze (i) as containing a five place predicate (Davidson 1967).

(7) In the philosophy of mind, intuitions about inverted spectrums, zombies, Chinese Rooms, and Mary the neuroscientist who has never seen the color red are widely invoked.

(8) In the philosophy of science, intuitions about explanation (the height of the flagpole explains the length of the shadow, but the length of the shadow does not explain the height of the flagpole) and confirmation (a black raven confirms the generalization that all ravens are black, but a white piece of chalk does not) play a central role in supporting or challenging theories of explanation and confirmation. 
This list is, of course, far from complete. It would be an easy task to add dozens of additional examples. ${ }^{2}$

What do the intuitions invoked in these examples have in common? As noted earlier, when things go well, people who are asked about these cases find themselves almost immediately disposed to offer an answer, though they are not consciously aware of engaging in any reasoning that leads them to that answer. We are inclined to think that this is all that these cases have in common. Thus we endorse a broadly inclusive account of philosophical intuition. On this point, we agree with Timothy Williamson, who maintains that more restrictive accounts of philosophical intuition will not reflect the way the term 'intuition' is invoked in contemporary philosophy.

Although we could decide to restrict the term 'intuition' to states with some list of psychological or epistemological features, such a stipulation would not explain the more promiscuous role the term plays in the practice of philosophy. (Williamson 2007, 218)

Of course, it could turn out that most or all of the mental states that philosophers have called 'philosophical intuitions' share interesting psychological properties that can't be detected without careful empirical work. But in an important recent paper, Jennifer Nado (2013a) argues that this is not the case. Nado reviews a growing body of scientific evidence suggesting that "the mental states which are generally assumed to fall under the category of 'intuition' likely comprise a highly heterogeneous group; from the point of view of psychology or of neuroscience, in fact, 'intuitions' appear to be generated by several fundamentally different sorts of mental processes." If Nado is right, and we are inclined to think she is, then one of the debates that will be center stage in the pages to follow, which focuses on the reliability of philosophical intuitions and the appropriateness of using philosophical intuitions as evidence in support of philosophical theories, will have to be fine-tuned in an important way. Rather than challenging, or defending, the epistemic status of most or all philosophical intuitions, we should be exploring the epistemic status of different sorts of philosophical intuitions that, according to our best psychology and neuroscience, are produced by different mental mechanisms.

Some critics of experimental philosophy, notably Williamson, have suggested that experimental philosophers are committed to the view that intuitions form a "psychological kind" (Forthcoming). But we find little evidence that researchers who view themselves as engaged in experimental philosophy think that intuitions form a psychological kind or are the product or a "special faculty" (Williamson, 2005, 18, 25). However, the idea of a faculty of intuition is endorsed by some of the critics of experimental philosophy, notably Hales (2012), and some defenders of the use of intuition as evidence in philosophy maintain that intuitions are a sui generis category of mental states (Bealer 1998; 2002).

Many philosophers who propose restrictive accounts of philosophical intuition are not concerned that their characterization of intuition excludes mental states that other philosophers have called "intuitions." Their goal is not to explain what Williamson 
describes as the "promiscuous" role that the term "intuition" plays in the practice of philosophy. Rather than trying to capture philosophical usage, typically those who offer restrictive accounts of intuition are trying to defend the use of intuitions as evidence in philosophy. In constructing their restrictive definitions of "intuition" they are trying to characterize those mental states that can legitimately be used as evidence in philosophical argumentation, and to exclude cases that they think should not be used, even if many philosophers would call those excluded cases "intuitions."

However, this is not the only motive for offering more restrictive accounts of intuition. As we noted earlier, Herman Cappelen tries to defend the view that philosophers don't use intuitions as evidence, and that the large number of philosophers who insist that they do are mistaken about their own practice. To make the case, Cappelen offers an account of intuitions that combines some of the most restrictive characterizations to be found in the literature, and then goes on to argue that intuitions characterized in that way are not used as evidence in philosophical argument. But since these restrictive characterizations impose what we take to be unreasonably demanding conditions on what is required for a judgment to be intuitive, Cappelen's exercise gives us no reason at all to doubt that intuitions are used as evidence in the philosophical discussions alluded to in (1) - (8) or in the specific cases that Cappelen considers. Rather, as Michael Devitt (2014) has noted, Cappelen gets his singularly implausible conclusion by proposing an account of intuition based on theoretically motivated philosophical accounts of intuition, rather than by trying to characterize paradigm cases of what philosophers call "intuitions." ${ }^{3}$

Though this is not the place for a detailed critique of Cappelen's overly restrictive account of intuition, or the role it plays in his polemical strategy, a single example may serve to illustrate the problem with his approach. As Cappelen rightly notes, a number of philosophers who defend the use of intuitions as evidence in philosophy maintain that "intuitive judgments must be based solely on conceptual competence." (Cappelen 2012, 9) As an illustration, he quotes Ludwig (2010).

It is only if a judgment is solely an expression of one's competence in the contained concepts and their mode of combination that it counts as an apprehension of a conceptual or a priori truth. Insofar as we think of intuitions as insights into conceptual truths [as Ludwig does], they are to be conceived as judgments or beliefs which are the product of our competence in the deployment of the concepts involved. (Ludwig 2010, 433; material in brackets added by Cappelen)

Another author cited by Cappelen is Sosa. Here's how Sosa makes the point.

I will presuppose ... a conception of intuitions as intellectual seemings of a certain sort, as attractions to assent derived from the sheer understanding of the propositions involved. (Sosa, 2007b)

Though it is not entirely clear how these passages are to be interpreted, on what is perhaps the most natural reading, they entail that a judgment (or a belief or a seeming) that is 
influenced by factors other than conceptual competence or "sheer understanding of the propositions involved" will not count as an intuition. Among those factors, surely, are the order in which cases are presented, the messiness of the room in which the intuition is generated, and whether or not the person who has the intuition has recently used an antiseptic hand cleaner. But, as we will see in §3.2, all of these factors, and lots of others, have been shown to influence people's responses to familiar philosophical thought experiments. Moreover, these influences are almost always covert - people have no awareness that their responses are being affected. To establish that these factors are influencing people's judgments (or that they aren't) requires well designed and carefully controlled experiments. So if the absence of influences like these is required for a judgment (or belief or seeming) to be an intuition, then we can't tell whether or not intuitions are being used in ordinary philosophical dialogue without doing sophisticated experiments. And we certainly can't show that intuitions were being utilized in the decades old philosophical discussions that Cappelen analyzes to make his case that philosophers do not rely on intuitions as evidence. But this casts no doubt at all on the widely held belief that intuitions do play an important role in philosophical argumentation. Rather, what it shows is that if one adopts an extremely demanding account of the conditions that a judgment must meet to qualify as an intuition, then it will be all but impossible to show that intuitions have been invoked in important philosophical exchanges.

\section{Why do experimental philosophers want to study philosophical intuitions using the methods of empirical science?}

\subsection{The Positive Program}

We turn now to the second question posed earlier. Broadly speaking, we think experimental philosophers can be divided into two clusters, and the people in these clusters answer this question in quite different ways. ${ }^{4}$ One group, which was, and continues to be, inspired by the pioneering work of Joshua Knobe $(2003 ; 2005 ; 2010)$, answers the question by noting that, in one guise or another, conceptual analysis has always played a central role in philosophy, and that intuitions are typically invoked as an important source of evidence for (or against) a proposed conceptual analysis. Why are intuitions useful as evidence in conceptual analysis? We think that many philosophers would endorse something like the answer proposed by Alvin Goldman.

It's part of the nature of concepts ... that possessing a concept tends to give rise to beliefs and intuitions that accord with the contents of the concept. If the content of someone's concept F implies that F does (doesn't) apply to example $\mathrm{x}$, then that person is disposed to intuit that $\mathrm{F}$ applies (doesn't apply) to $\mathrm{x}$ when the issue is raised in his mind.... [P]ossessing a concept makes one disposed to have pro-intuitions toward correct applications and con-intuitions toward incorrect applications - correct, that is, relative to the contents of the concept as it exists in the subject's head. (Goldman 2007, 14$15)^{5}$ 
This account is quite similar to the standard account that Chomskian linguists offer for the use of linguistic intuitions in confirming or disconfirming a theory about the grammar of a person's "I-language" - the language whose grammar is actually represented in the person's mind (Chomsky 1986). ${ }^{6}$ Linguistic intuitions about a sentence, Chomskians maintain, typically reflect what the speaker's mentally represented grammar entails about the sentence. So, for example, if the grammar entails that the sentence is grammatical, speakers will be disposed to intuit that the sentence is acceptable, and if the grammar entails that the sentence is not grammatical, then speakers will be disposed to intuit that the sentence is not acceptable. However, as Chomsky and his followers have long noted, a speaker's linguistic intuitions are not an infallible source of information about the grammar of the speaker's I-language. Failures of attention, limits of short term memory, and a variety of other factors can produce what Chomsky calls "performance errors" leading to linguistic intuitions that do not reflect the speaker's underlying grammatical competence. Much the same can happen with philosophical intuitions. As Goldman points out, there are a number of ways in which "intuitions can go wrong." For example, the person having the intuition may have a mistaken belief about some detail of the example, or she may "lose track of some features of the example while mentally computing the applicability of F to it." For our purposes, however, the most interesting source of performance errors that Goldman mentions is that the person having the intuition "might have a false theory about her concept of F, and this theory may intrude when forming an application intuition" - i.e. an intuition about whether the concept applies to an example specified in a thought experiment (Ibid). As Goldman goes on to note, this is a danger to which philosophers are particularly vulnerable, since they have often have well elaborated theories about the concepts they are attempting to analyze.

Knobe, and many experimental philosophers who have followed in his footsteps, in what has been dubbed "the positive program" 7 of experimental philosophy, are motivated to explore intuitions experimentally because they think that by doing so they can do a better job of conceptual analysis. They can avoid some of the idiosyncrasies, biases and performance errors that are likely to confront philosophers who attend only to their own intuitions and the intuitions of a few professional colleagues who read the same journals and who may have prior commitments to theories about the concepts under analysis. By collecting the intuitions of a substantial number of non-philosophers, Knobe maintains, we may discover important facts about ordinary concepts that have gone unnoticed by philosophers using more traditional methods of conceptual analysis.

Knobe's own groundbreaking discovery of "the side-effect effect" provides an excellent example of the way in which experimental philosophy can lead to unexpected discoveries about philosophically important concepts. Prior to Knobe's work, there was a substantial philosophical literature aimed at analyzing the concept of intentional action. But the philosophers who contributed to that literature assumed that intentional action was a purely descriptive concept, and that whether or not the outcome of an action was intentional would depend entirely on the psychological states that led to the action. Knobe suspected that non-philosophers' intuitions about foreseen side-effects of actions would also be affected by the moral valence of the side-effect, though philosophers might not have 
these intuitions because of the influence of philosophical theories in this area. To test his hypothesis, Knobe (2003) presented subjects with scenarios like the following:

The vice-president of a company went to the chairman of the board and said, "We are thinking of starting a new program. It will help us increase profits, but it will also harm the environment."

The chairman of the board answered, “I don't care at all about harming the environment. I just want to make as much profit as I can. Let's start the new program."

They started the new program. Sure enough, the environment was harmed.

Another group of subjects was presented with the identical text, except that 'harm', 'harming' and 'harmed' were systematically replaced by 'help,' 'helping' and 'helped.' In the harm case, participants were asked how much blame the chairman deserved (on a scale from $0-6$ ) and whether he intentionally harmed the environment. In the help case, participants were asked how much praise the chairman deserved (on a scale from $0-6$ ) and whether he intentionally helped the environment. The results, which have been replicated many times, were quite striking. In the harm case, $82 \%$ said the chairman brought about the side-effect intentionally. But in the help case, $77 \%$ said the chairman did not bring about the side-effect intentionally. This remarkable finding has led to an on-going debate about what factors are responsible for this effect (Adams and Steadman 2004; Nadelhoffer 2006; Nichols and Ulatowski 2007; Alicke 2008; Machery 2008; Sripada 2010). Though not everyone agrees, Knobe and many others think that the finding reflects a previously unsuspected feature of the ordinary concept of intentional action - a feature that had not been noticed by philosophers who relied on their own intuitions. ${ }^{8,9}$

The take home message for this section of our paper is that the positive program in experimental philosophy shares the goal of the substantial part of traditional philosophy that is concerned with the analysis of important philosophical concepts. Moreover, the positive program and the philosophical tradition agree that intuitions about real and hypothetical cases provide an important, though defeasible source of evidence for conceptual analyses. Experiments are important because they can reveal features of philosophically important concepts - like the link between moral valance and the concept of intentional action - that, for one reason or another, philosophers have failed to notice. In principle, experiments can also be useful when philosophers disagree about cases. If most non-philosophers' intuitions about the disputed cases coincide with the intuitions of one group of philosophers, then we have some reason to believe that the intuitions of the other group of philosophers - those who do not share the intuition of "the folk" - are performance errors, or that this group of philosophers do not share the concept that is guiding the intuitions of the folk and the other philosophers. This is a theme we will return to in section $\$ 3.2 .10$

\subsection{The Negative Program}


The second answer to the question: Why do experimental philosophers want to study philosophical intuitions using the methods of empirical science? is provided by what is often called the "negative program." The negative program has implications for philosophical projects whose goal is conceptual analysis, and we will attend to these at the end of this section. However, the negative program is best set out against the backdrop of a different account the philosophical goals that many philosophers are pursuing. The analysis of concepts has long played an important role in philosophy, and in the middle years of the $20^{\text {th }}$ century, some philosophers, influenced by Logical Positivism and "ordinary language philosophy," held the view that this was the main job of philosophy. But many philosophers, both historical and contemporary, would reject this view. According to Ernest Sosa, for example,

It is often claimed that analytic philosophy appeals to armchair intuitions in the service of "conceptual analysis." But this is deplorably misleading. The use of intuitions in philosophy should not be tied exclusively to conceptual analysis. Consider some main subjects of prominent debate: utilitarian versus deontological theories in ethics, for example, or Rawls's theory of justice in social and political philosophy, or the externalism/internalism debate in epistemology; and many others could be cited to similar effect. These are not controversies about the conceptual analysis of some concept. They seem moreover to be disputes about something more objective than just a description or analysis of our individual or shared concepts of the relevant phenomena. Yet they have been properly conducted in terms of hypothetical examples, and intuitions about these examples. The questions involved are about rightness, or justice, or epistemic justification. Some such questions concern an ethical or epistemic subject matter, and not just our corresponding concepts. (Sosa 2007, 100)

Sosa is surely right that many analytic philosophers would reject the idea that philosophy is principally concerned with the analysis of concepts. Rather, they would insist, many epistemologists are concerned with the nature of knowledge - what knowledge is - not with some person's or group's concept of knowledge, that many moral and political philosophers are concerned with the nature of justice - what justice is - not with some person's or group's concept of justice, and so on for many other branches of philosophical inquiry.

When intuitions are used in conceptual analysis, the usual assumption, as we saw in $\S 3.1$, is that our intuition about whether a concept applies to a particular case is good, though not infallible, evidence about whether our concept really does apply to the case. In conceptual analysis, as in linguistics, intuitions are used as evidence about the underlying psychological states that typically play a central role in causing the intuition. But when intuitions about hypothetical cases are used to study the nature of knowledge or justice, or the nature of causation or reference or intentionality, rather than some person's or group's concepts of these phenomena, philosophers typically make a very different assumption. They assume that the contents of philosophical intuitions are likely to be true. Thus, for example, it is assumed that if we have the intuition that the protagonist in a typical Gettier case does not know the specified proposition, $\mathrm{p}$, then it is likely that a person in that 
situation does not know that $\mathrm{p}$, and any theory about the nature of knowledge that entails the protagonist does know that $p$ is challenged. Similarly, it is assumed that if our intuition in a "Magistrate and the Mob" case is that it is morally wrong for the magistrate to knowingly find the innocent man guilty in order to prevent a violent riot, then it probably is morally wrong, and a moral theory that entails that it is wrong would be supported. Some philosophers find these assumptions deeply puzzling. How, they ask, could intuition provide generally reliable information about knowledge or justice or causation? ${ }^{11}$ But philosophers like Sosa and Hales, who defend the practice of using intuitions in this way, and the assumption on which it rests, maintain that we rely on a largely parallel assumption when we use perceptual evidence (Sosa 2007; Hales 2012).

In the previous paragraph, we followed the ubiquitous practice of talking about "our" intuitions and what follows if "we" have a specified intuition, without ever saying who "we" are. The tacit assumption behind this practice seems to be that everyone (or almost everyone) will have the same intuitions. As we noted earlier, this is an assumption that goes all the way back to Plato. Socrates insists that "no one would say that I ought [to return the weapons] or that I should be right in doing so, any more than they would say that I ought always to speak the truth to one who is in his condition" (Plato 1892; italics added). But it is an assumption about which some philosophers have long been suspicious. ${ }^{12}$ Starting in the final decade of the $20^{\text {th }}$ century, the work of Richard Nisbett and other cultural psychologists demonstrated that there are important differences in the perception, memory and cognition of people in different cultures (Nisbett 2003; Henrich, Heine, and Norenzayan 2010; Heine 2011). In light of these findings, it is hard to see why we should blithely assume that people in different cultures would share the same philosophical intuitions. The assumption seems to be making a bold empirical claim that is susceptible to empirical exploration. So in the last few years of the last century, a group of philosophers at Rutgers University decided to test the assumption (Weinberg, Nichols, and Stich 2001; Nichols, Stich, and Weinberg 2003; Machery et al. 2004). These were among the earliest studies in experimental philosophy's negative program, and many philosophers found the results quite unsettling. In some cases, it seemed, people with different cultural backgrounds had significantly different intuitions about standard philosophical thought experiments. If this is right, then it poses an important challenge to the use of intuitions that Sosa endorses in the passage quoted above. For, as Sosa himself noted, if one group of people have the intuition that (say) the protagonist in a Gettier case does know that p, and another group have the intuition that the protagonist does not know that $\mathrm{p}$, then they can't both be right. So without a well-supported "theory of error" that explains why the people or cultures who disagree with us are mistaken, the finding of cultural or individual differences in philosophical intuition makes the assumption that "our" intuitions are very likely to be true more than a bit problematic (Sosa 2007).

During the last half decade experimental philosophers, along with a number of psychologists, have become increasingly interested the idea that there may be cultural differences in people's intuitive responses to philosophically important thought experiments, and this has led to a growing body of experimental work that has also begun to explore differences in intuitions across a variety of other demographic categories, including gender, age, personality, academic affiliation, and native language (Abarbanell 
and Hauser 2010; Ahlenius and Tännsjö, 2012; Buckwalter and Stich 2013; Colaço et al. 2014; Costa et al. 2014; Feltz and Cokely 2009; Machery, Olivola, and De Blanc 2009; Machery et al. under review; Nagel, San Juan, and Mar 2013; Starmans and Friedman 2103, 2014; Turri 2013; Vaesen, Peterson, and Van Bezooijen 2013). Some of these studies report partially conflicting findings, most have small sample sizes, and some raise other methodological issues. ${ }^{13}$ So at this point, we don't think any firm conclusions can be drawn. What is clear is that if different demographic groups do indeed have substantially different intuitions about the sorts of hypothetical cases that philosophers rely on to test their theories, then the negative program in experimental philosophy will pose a major challenge to the traditional philosophical methodology that uses intuitions as evidence for conclusions about the nature of knowledge, justice, causation, reference and other philosophically important phenomena.

Demographic differences have not been the only focus of work in the negative program. Other studies have found that the order in which questions are asked, philosophically insignificant differences in the wording of the question, and the physical circumstances in which the intuitions are solicited can all have an effect on the intuitions that people report. ${ }^{14}$ All of this is bad news for the standard philosophical assumption that the contents of people's intuitions are very likely to be true. As Walter Sinnott-Armstrong has noted, in discussing order effects in moral intuitions,

The truth about what is morally right or wrong in the cases did not vary with [the order in which they were presented]. Hence moral [intuitions] fail to track the truth and are unreliable insofar as they are subject to such order effects. (Sinnott-Armstrong 2008, 67)

Thus far, our discussion of the negative program has focused on the use of intuitions in philosophical projects whose goal is not conceptual analysis. Before moving on, let's briefly consider the implications of the negative program for philosophical projects whose goal is conceptual analysis. There is, we think, an important distinction between order effects, wording effects and effects of physical circumstances, on the one hand, and demographic differences on the other. If there are order, wording or physical circumstance effects on people's intuitions about philosophically important cases, this poses a serious problem for the conceptual analyst. For, as Goldman (2007) pointed out, conceptual analysis typically assumes that "[i]f the content of someone's concept F implies that F does (doesn't) apply to example $\mathrm{x}$, then that person is disposed to intuit that $\mathrm{F}$ applies (doesn't apply) to $\mathrm{x}$ when the issue is raised in his mind." And if order, philosophically insignificant wording differences or physical circumstances have a substantial effect on whether people intuit that $\mathrm{F}$ applies to example $\mathrm{x}$, then this assumption is mistaken.

The situation is interestingly different for demographic differences. Though there is no shortage of disagreement about how concepts are to be individuated, on one influential view, demographic differences in intuitions about philosophically important cases would be good evidence that the two groups had different concepts. Here is how Frank Jackson makes the point. 
I have occasionally run across people who resolutely resist the Gettier cases. Sometimes it has seemed right to accuse them of confusion - they haven't properly understood the cases ... - but sometimes it is clear that they are not confused; what we then learn from the stand-off is simply that they use the word 'knowledge' to cover different cases from most of us. In these cases it is, it seems to me, misguided to accuse them of error (unless they go on to say that their concept of knowledge is ours). (Jackson 1998, 32)

If it turns out that different demographic groups have different concepts of knowledge, or justice, or moral permissibility or causation, it would, we think, be a fascinating and important discovery. But it would not pose any major challenge to philosophers engaged in conceptual analysis. They would simply have to be more careful to say whose concepts they were analyzing.

This is not quite the end of the story, however. For while some philosophers pursue conceptual analysis as an end in itself, others want to use the analyzed concepts in other philosophical projects. And here demographic variation poses a problem. If, for example, a philosopher proposes to use the concept of justice or knowledge in formulating a normative principle, and if the concept invoked is different in different demographic groups, then the philosopher must specify which version of the concept she is invoking in her normative principle. She must also be prepared to explain why that version of the concept is the right one to use. Why is your concept of knowledge or justice better, or more appropriate, than the version used by people in other groups? Underscoring the need to address questions like this is, we believe, one of the most valuable contributions of the negative program.

\section{The Expertise Defense}

There have been a number responses to the challenge posed by experimental philosophy's negative program. In this final section, we will focus on the one that has probably received the most attention. Following the lead of other authors, we will call it "the expertise defense." The core idea of this response is that the studies that putatively show that philosophical intuitions are significantly influenced by irrelevant factors like the order in which cases are presented, philosophically unimportant differences in the wording of the cases, or the physical circumstances in which the cases are presented pose no challenge to the philosophical practice of using intuitions as evidence, because the experiments are gathering data from the wrong participants. These studies typically collect data from students, or internet users, or people strolling in public parks. But, the expertise defense maintains, when practicing their craft, philosophers do not rely on the intuitions of ordinary folk. Rather, they rely on their own intuitions and those of other professional philosophers. And that, the response continues, is as it should be, because philosophers are experts in understanding and generating intuitions about philosophical thought experiments. 
It is important to keep in mind that the expertise defense is proposed as a response to the challenged posed by studies showing that the intuitions of ordinary folk are influenced by irrelevant factors like order, minor differences in wording, and physical circumstances. In order to respond to that challenge, it is not sufficient to argue that philosophers' intuitions about philosophical thought experiments are more likely to be true than the intuitions of ordinary of ordinary folk - though to the best of our knowledge, that latter claim has never been plausibly defended. To address the irrelevant influences challenge, the expertise defense must argue that philosophers' intuitions are less likely to be subject to irrelevant influences. This point has been clearly recognized by authors on both sides of the debate. For example, Horvarth, who endorses the expertise defense, writes:

Why should professional philosophers grant ... that their own intuitions about hypothetical cases vary equally with irrelevant factors as those of the folk? Surely, no chess grandmaster, mathematician or physicist would grant anything remotely like that to an experimental psychologist." (Horvath 2010)

And Nado, a critic of the expertise defense, makes the point this way:

The "expertise defense" is a particular strategy for meeting the experimental challenge. The basic claim is that the proponents of the experimental challenge have illicitly assumed that the variation that has been found on untrained subjects will also hold for the intuitive judgments of trained, professional philosophers. On the contrary, the defenders claim, trained philosophers have special skills which will help them resist the problematic variation." (Nado 2013b)

The challenge posed by the expertise defense is a reasonable one. It is surely possible that the intuitions of professional philosophers are much less susceptible to irrelevant influences than the intuitions of other people. But whether or not it is true is clearly an empirical question, and thus far the advocates of the expertise defense have offered no empirical evidence. Rather, they have supported their claim with speculation and analogies. Until recently, the critics of the expertise defense had not done much better. But in the last few years, several studies have appeared that were designed to test the claim that philosophers' intuitions exhibit less irrelevant variation than the intuitions of nonphilosophers. We will briefly consider three of these - the first looking at order effects, the second at a minor difference in wording, and the third focused on the physical circumstances in which intuitions are elicited.

Eric Schwitzgebel and Fiery Cushman (2012), used an on line survey that required participants to make moral judgments about a collection of scenarios relevant to three topics that are widely discussed in the philosophical literature: the doctrine of double effect, the action-omission distinction, and the phenomenon of moral luck. They also asked participants questions designed to assess whether they endorsed moral principles related to each of these topics. The order in which the scenarios were presented to participants was varied. So, for example, some participants were presented with a "push" version of a 
trolley problem before being presented with a "switch" version, while other participants saw these scenarios in the opposite order. The participants included academic philosophers who had completed an MA or a PhD in philosophy (many of them, including $91 \mathrm{PhDs}$, reported ethics as an area of specialization or an area of competence), academics who were not philosophers, and people who were not academics. Not surprisingly, the nonphilosophers showed significant order effects for all three types of scenario. But what about the philosophers? Schwitzgebel and Cushman report that "in our summary measure of order effects across all scenario judgments, philosophers and ethics PhDs trended marginally higher than the comparison groups." They go on to observe that "[i]t is particularly striking that philosophical expertise did not reduce order effects for cases intended to target the doctrine of double effect, the action-omission distinction, and the principle of moral luck, given that these philosophical principles are widely discussed in terms of hypothetical scenario comparisons very much like those we presented to our participants." (148) The results on the endorsement of moral principles were even more striking. "Aggregating across all three principles, we found a significant order effect on philosophers' endorsements of general moral principles that was three times larger than the corresponding, non-significant effect for non-philosophers." (149)

Let's turn, now, to wording effects. Tobia et al. (2012) focused on an effect called the "actor/observer bias" that has been studied by a number of psychologists (Jones and Nisbett 1971; Saulnier and Perlman, 1981; Fielder et al. 1995; Choi and Nisbett 1998). This earlier work demonstrated that, in many cases, people will respond differently to scenarios depending on whether the scenario depicts the experimental participant as the actor or the observer. In their study, Tobia and colleagues borrowed the following well known scenario from Smart and Williams $(1978,98)$.

You find yourself in the central square of a small South American town. Tied up against the wall are twenty natives, most terrified, a few defiant, in front of them several armed men in uniform. A heavy man in a sweat stained khaki shirt turns out to be the captain in charge and, after a good deal of questioning which establishes that you got there by accident while on a botanical expedition, explains that the natives are a random group of the inhabitants who, after recent acts of protest against the government, are just about to be killed to remind the other possible protesters of the advantages of not protesting. However, since you are an honored visitor from another land, the captain is happy to offer you a guest's privilege of killing one of the natives yourself. If you accept, then as a special mark of the occasion, the other natives will be let off. Of course, if you refuse, then there is no special occasion, and Pedro here will do what he was about to do when you arrived, and kill them all. With some desperate recollection of childhood fiction, you wonder whether if you got hold of the gun, you could hold the captain, Pedro and the rest of the soldiers at bay, but it is quite clear from the circumstances that nothing of that kind is going to work: any attempt at that sort of thing will mean that you will also be killed along with all of the natives. The men against the wall, and the other villagers, understand the situation, and are obviously begging you to accept. What should you do? 
Half of the participants were presented with this text and asked:

Do you think that in these circumstances you are morally obligated to shoot and kill the one native in order to save the others?

In the scenario presented to the remainder of the participants, 'you' was replaced with 'Jim' and the necessary grammatical changes were made. Undergraduate participants showed a large actor-observer effect: $19 \%$ said the action was morally obligatory for themselves, while $53 \%$ said it was morally obligatory for Jim. Professional philosophers also showed a large actor-observer effect, though it was in the opposite direction!

In another study, Tobia et al. (2013) looked at the effect of physical circumstances on the moral intuitions of philosophers and non-philosophers. They borrowed some of the (slightly kinky) "purity violations" that had been used in an earlier study by Helzer and Pizarro (2011), such as:

While house sitting for his grandmother, a man and his girlfriend have sex on his grandmother's bed.

Participants were asked to rate each action on a scale from 1 ("not at all wrong") to 7 ("totally wrong"). Some participants were surveyed using questionnaires that had previously been sprayed with distilled water; others were surveyed using questionnaires that had been sprayed with Spring Waterfall Scent Lysol spray. All the questionnaires were left to dry before being used. The scent remaining on the Lysol questionnaires was very hard to notice. None of the participants made any mention of it. But the scent had a significant effect on the judgments of both student participants and professional philosophers.

The expertise defense predicts that the intuitions of professional philosophers will be less susceptible to irrelevant influences than the intuitions of ordinary folk. In the three studies we reviewed in this section, that prediction is mistaken. More work is needed, of course, since any single study could be a fluke or outlier. But the empirical evidence against the expertise defense is growing. In addition to the three studies surveyed here, Knobe and Samuels (2013) report another order effect on philosophers' intuitions, Machery (2013) found an effect of disciplinary background between linguists and philosophers, Vaesen, Peterson, and Van Bezooijen (2013) found an effect of native language on philosophers' epistemic intuitions, Schulz, Cokely, and Feltz (2011) found an effect of personality on experts' free will intuitions, and Tobia and Stich (ms.) found an effect of font on philosophers' intuitions about knowledge. We encourage continued research bearing on questions and claims of expertise, but the evidence currently available gives us no reason to believe that philosophical training shields philosophers' intuitions from several irrelevant influences. If that's right, then experimental philosophy poses a major challenge to one of the main sources of evidence that philosophers have relied on throughout the history of western philosophy. 


\section{$\underline{\text { References }}$}

Abarbanell, Linda, and Marc D. Hauser. 2010. "Mayan Morality: An Exploration of Permissible Harms." Cognition, 115: 207-224. DOI:10.1016/j.cognition/2009/12/007.

Adams, Fred, and Annie Steadman. 2004. "Intentional Action in Ordinary Language: Core concept or pragmatic understanding?" Analysis, 64(282): 173-181. DOI:10.111/j.14678284.2004.00480.x.

Ahlenius, Henrick, and Tännsjö, Torbjörn. 2012. "Chinese and Westerners Respond Differently to the Trolley Dilemmas." Journal of Cognition and Culture, 12 (3-4): 195201. DOI:10.1163/15685373-12342073.

Alexander, Joshua, Ron Mallon, and Jonathan Weinberg. 2010. "Accentuate the Negative." Review of Philosophy and Psychology, 1: 297-314. DOI:10.1007/s13164-009-0015-2.

Alexander, Joshua. 2012. Experimental Philosophy: An Introduction. Cambridge, UK: Polity Press.

Alfano, Mark, and Don Loeb. 2014. "Experimental Moral Philosophy." In The Stanford Encyclopedia of Philosophy (Summer 2014 Edition), edited by Edward N. Zalta, URL = $<$ http://plato.stanford.edu/archives/sum2014/entries/experimental-moral/>.

Alicke, Mark. 2008. “Blaming Badly.” Journal of Cognition and Culture, 8(1): 179-186. DOI:10.1163/15770908X289279.

Andow, James. Forthcoming. "How 'Intuition' Exploded.” Metaphilosophy.

Batson, C. D. 1991. The Altruism Question: Toward a Social-Psychological Answer. Hillsdale, NJ: Erlbaum Associates.

Batson, C.D. 2011. Altruism in Humans. New York: Oxford University Press.

Bealer, George. 1998. "Intuition and the Autonomy of Philosophy." In Rethinking Intuition, edited by Michael DePaul and William Ramsey. Lanham, MD: Rowman and Littlefield.

Bealer, George. 2002. "Modal Epistemology and the Rationalist Renaissance." In Conceivability and Possibility, edited by Tamar Gendler and John Hawthorne. New York: Oxford University Press.

Brandt, Richard B. 1954. Hopi Ethics: A Theoretical Analysis. Chicago: University of Chicago Press.

Buckwalter, Wesley, and Stephen Stich. 2013. “Gender and Philosophical Intuition." In Experimental Philosophy, vol. 2, edited by Joshua Knobe and Shaun Nichols. New York: Oxford University Press.

Chalmers, David J., and Frank Jackson. 2001. "Conceptual Analysis and Reductive Explanation." Philosophical Review, 110, 3, 315-360. D0I:10.1215/00318108-110-3315.

Chalmers, David J. 2014. "Intuitions in Philosophy: A Minimal Defense." Philosophical Studies, 171(3): 535-544. DOI:10.1007/s11098-014-0288-x.

Cappelen, Herman. 2012. Philosophy Without Intuitions. Oxford: Oxford University Press. 
Choi, Incheol., and Richard Nisbett. 1998. "Situational Salience and Cultural Differences in the Correspondence Bias and Actor-Observer Bias." Personality and Social Psychology Bulletin, 24(9): 949-960. DOI:10.1177/0146167298249003.

Chomsky, Noam. 1986. Knowledge of Language. New York: Praeger.

Colaço, David, Wesley Buckwalter, Stephen Stich and Edouard Machery. 2014. "Epistemic Intuitions in Fake-Barn Thought Experiments." Episteme, 11(2): 199-212. DOI:10.1017/epi.2014.7.

Costa, Albert, Alice Foucart, Sayuri Hayakawa, Melina Aparici, Jose Apesteguia, Joy Heafner, and Boaz Keysar. 2014. "Your Morals Depend on Language." PLoS ONE 9(4): e94842. DOI:10.1371/journal.pone.0094842.

Davidson, Donald. 1967. "The Logical Form of Action Sentences." In The Logic of Decision and Action, edited by Nicholas Rescher, 81-120. Pittsburgh: University of Pittsburgh Press.

Devitt, Michael. 2014. Abstract of "Philosophy With Intuitions: A Response to Herman Cappelen." a lecture given at St. Andrews, Spring 2014, (unpublished manuscript).

Feltz, Adam. and Edward T. Cokely. 2009. "Do Judgments About Freedom and Responsibility Depend on Who You Are? Personality Differences in Intuitions About Compatibilism and Incompatibilism." Consciousness and Cognition, 18(1): 342-350. DOI:10.1016/j.concog.2008.08.001.

Fiedler, Klaus, Guin R. Semin, Catrin Finkenauer, and Ingnd Berkel. 1995. "Actor-Observer Bias in Close Relationships: The Role of Self-Knowledge and Self-Language." Personality and Social Psychology Bulletin, 21(305): 525-538. D0I:10.1177/0146167295215010.

Goldman, Alvin. 2007. "Philosophical Intuitions: Their Target, Their Source, and Their Epistemic Status." Grazer Philosophische Studien, 74: 1-26. DOI:10.1.1.124.8547.

Hales, Steven D. 2012. "The Faculty of Intuition." Analytic Philosophy, 53: 180-207. DOI:10.111/j.2153-960X.2012.00560.x.

Heine, Steven J. 2011. Cultural Psychology, Second Edition. New York: W. W. Norton \& Company.

Helzer, Erik G. and David A. Pizarro. 2011. "Dirty liberals! Reminders of Physical Cleanliness Influence Moral and Political Attitudes." Psychological Science, 22: 517522. DOI:10.1177/0956797611402514.

Henrich, Joseph, Steven J. Heine, and Ara Norenzayan. 2010. "The Weirdest People in the World?" Behavioral and Brain Sciences, 33(2-3): 61-83.

DOI:10.1017/S0140525X0999152X.

Hintikka, Jaakko. 1999. “The Emperor's New Intuitions.” Journal of Philosophy, 96(3): 127147.

Horvath, Joachim. 2010. "How (not) to react to experimental philosophy." Philosophical Psychology, 23(4): 447-480. DOI:10.1080/09515089.2010.505878. 
Jackson, Frank. 1998. From Metaphysics to Ethics: A Defence of Conceptual Analysis. Oxford: Clarendon Press.

Jones, Edward E., and Richard E. Nisbett. 1971. The Actor and the Observer: Divergent Perceptions of the Causes of Behavior. New York: General Learning Press.

Knobe, Joshua. 2003. "Intentional Action and Side Effects in Ordinary Language." Analysis, 63: 190-193. DOI:10.111/1467-8284.00419.

Knobe, Joshua. 2005. "Theory of Mind and Moral Cognition: Exploring the Connections." Trends in Cognitive Sciences, 9(8): 357-359. DOI:10.1016.j.tics.2005.06.011.

Knobe, Joshua. 2010. "Person as Scientist, Person as Moralist." Behavioral and Brain Sciences, 33(4): 315-329. DOI:10.1017/S010525X10000907.

Knobe, Joshua. this volume. "Experimental Philosophy is Cognitive Science."

Knobe, Joshua, and Richard Samuels. 2013. "Thinking Like a Scientist: Innateness as a Case Study." Cognition, 126(1): 72-86. DOI:10.1016/j.cognition.2012.09.003.

Knobe, Joshua, and Shaun Nichols. 2008. "An Experimental Philosophy Manifesto." In Experimental Philosophy, vol. 1, edited by Joshua Knobe and Shaun Nichols. New York: Oxford University Press.

Ladd, John. 1957. The Structure of a Moral Code: A Philosophical Analysis of Ethical Discourse Applied to the Ethics of the Navaho Indians. Cambridge, MA: Harvard University Press.

Liao, S. Matthew, Alex Wiegmann, Joshua Alexander, and Gerard Vong. 2012. "Putting the trolley in order: Experimental philosophy and the loop case." Philosophical Psychology, 25(5): 661-671. DOI:10.1080/09515089.2011.627536.

Ludwig, Kirk. 2007. “The Epistemology of Thought Experiments: First Person vs. Third Person Approaches." Midwest Studies in Philosophy, 31: 128-159.

Machery, Edouard, Ron Mallon, Shaun Nichols, and Stephen Stich. 2004. "Semantics, crosscultural style." Cognition, 92: B1-B12. DOI:10.1016/j.cognition.2003.10.003.

Machery, Edouard 2008. "The Folk Concept of Intentional Action: Philosophical and Experimental Issues." Mind \& Language, 23(2): 165-189. D0I:10.111/j.14680017.2007/00336.x.

Machery, Edouard, Christopher Y. Olivola, and Molly De Blanc. 2009. "Linguistic and metalinguistic intuitions in the philosophy of language." Analysis, 69: 689-694. DOI:10.1093/analys/anp095.

Machery, Edouard 2012. "Expertise and Intuitions About Reference." Theoria, 73: 37-54. DOI:10.1387/theoria.3482.

Machery, Edouard, Stephen Stich, David Rose., Amita Chatterjee, Kaori Karasawa, Noel Struchiner, S. Sirker, Naoki Usui, and Takaaki Hashimoto. Under review. "Gettier Across Cultures."

Malmgren, Anna-Sara. 2013. "Review of: Herman Cappelen, Philosophy Without Intuitions." Notre Dame Philosophical Reviews. http://ndpr.nd.edu/news/39362-philosophywithout-intuitions/ 
Nadelhoffer, Thomas. 2006. "Bad Acts, Blameworthy Agents, and Intentional Actions: Some Problems for Jury Impartiality.” Philosophical Explorations, 9: 203-219.

DOI:10.1080/13869790600641905.

Nado, Jennifer. 2013a. "Why Intuition?" Philosophy \& Phenomenological Research, 86: 1541. DOI:10.1111/j.1933-1592.2012.00644.x.

Nado, Jennifer. 2013b. "Philosophical Expertise and Scientific Expertise." Paper presented at Buffalo Annual Experimental Philosophy Conference 2013, University of Buffalo, October 12th, 2013.

Nagel, Jennifer., Valerie San Juan, and Raymond A. Mar. 2013. "Lay Denial of Knowledge for Justified True Beliefs." Cognition, 129: 652-661. DOI:10.1016/j.cognition.2013.02.008.

Nahmias, Eddy, Stephen Morris, Thomas Nadelhoffer, and Jason Turner. 2005. "Surveying Freedom: Folk Intuitions about Free Will and Moral Responsibility." Philosophical Psychology, 18(5): 561-584. DOI:10.1080/09515080500264180.

Nahmias, Eddy, Stephen Morris, Thomas Nadelhoffer, and Jason Turner. 2006. "Is Incompatibilism Intuitive?" Philosophy and Phenomenological Research, 73(1): 28-53. DOI:10.1111/j.1933-1592.2006.tb00603.x.

Nichols, Shaun, Stephen Stich, and Jonathan Weinberg. 2003. "Meta-Skepticism: Meditations on Ethno-Epistemology." In The Skeptics, edited by Steven Luper, 227-247. Aldershot, U.K.: Ashgate Publishing.

Nichols, Shaun, and Joseph Ulatowski. 2007. "Intuitions and Individual Differences: The Knobe Effect Revisited." Mind \& Language, 22(4): 346-365. DOI:10.111/j.14680017.2007.00312.x.

Nisbett, Richard. 2003. The Geography of Thought: How Asians and Westerners Think Differently... and Why. New York: The Free Press.

Plato. 1892. The Dialogues of Plato, translated by Benjamin Jowett. New York: Random House.

Pust, Joel. 2000. Intuitions as Evidence. New York: Garland Publishing.

Rose, David and David Anks. 2013. "In Defense of a Broad Conception of Experimental Philosophy." Metaphilosophy, 44: 512-532. DOI:10.1111/meta.12045.

Saulnier, Kathryn, and Daniel Perlman. 1981. "The Actor-Observer Bias is Alive and Well in Prison: A Sequel to Wells." Personality and Social Psychology Bulletin, 7: 559-564. DOI:10.1177/014616728174006.

Schnall, Simone, Jonathan Haidt, Gerald L. Clore, and Alexander H. Jordan. 2008. "Disgust as Embodied Moral Judgment." Personality and Social Psychology Bulletin, 34(8), 10691109. DOI:10.1177/0146167208317771.

Schulz, Eric, Edward T. Cokely, and Adam Feltz. 2011. "Persistent Bias in Expert Judgments About Free Will and Moral Responsibility: A Test of the Expertise Defense." Consciousness and Cognition, 20(4): 1722-1731. DOI:10.1016/j.concog.2011.04.007. 
Schwitzgebel, Eric, and Fiery Cushman. 2012. "Expertise in Moral Reasoning? Order Effects on Moral Judgment in Professional Philosophers and Non-Philosophers." Mind and Language, 27(2): 135-153. D0I:10.1111/j.1468-0017.2012.01438.x.

Sinnott-Armstrong, Walter. 2008. "Framing Moral Intuitions." In Moral Psychology, vol. 2, The Cognitive Science of Morality: Intuition and Diversity, edited by Walter SinnottArmstrong. Cambridge, MA: MIT Press.

Smart, J. J. C., and Bernard Williams. 1973. Utilitarianism: For and Against, Cambridge: Cambridge University Press.

Sosa, Ernest. 2007a. "Experimental Philosophy and Philosophical Intuition." Philosophical Studies, 132: 99-107. DOI:10.1007/s11098-006-9050-3.

Sosa, Ernest. 2007b. "Intuitions: Their Nature and Epistemic Efficacy." Grazer Philosophische Studien, 74(1): 51-67.

Sripada, Chandra. 2010. "The Deep Self Model and Asymmetries in Folk Judgments About Intentional Action." Philosophical Studies, 151: 159-176. DOI:10.1007/s11098-0099423-5.

Starmans, Christina, and Ori Friedman. 2012. "The Folk Conception of Knowledge." Cognition, 124: 272-283. DOI:10.1016/j.cognition.2012.05.017.

Starmans, Christina, and Ori Friedman. 2014. "No, no, KNOW! Academic Disciplines Disagree About the Nature of Knowledge." Paper presented at the Common-Sense Beliefs and Lay Theories Preconference at the Fifteenth Annual Society for Personality and Social Psychology, Austin, Texas.

Stich, Stephen. 1988. "Reflective Equilibrium, Analytic Epistemology and the Problem of Cognitive Diversity." Synthese, 74(3): 391-413. D0I:10.1007/BF00869637.

Stich, Stephen. 1990. The Fragmentation of Reason. Cambridge, MA: MIT Press.

Sytsma, Justin, and Edouard Machery. 2013. "Experimental Philosophy." In Encyclopedia of Philosophy and the Social Sciences, edited by Byron Kaldis, 318-320. Thousand Oaks, CA: SAGE.

Sytsma, Justin and Jonathan Livengood. Forthcoming. The Theory and Practice of Experimental Philosophy. Peterborough, Ontario: Broadview Press.

Tobia, Kevin P., Wesley Buckwalter, and Stephen Stich. 2012. “Moral Intuitions: Are Philosophers Experts?" Philosophical Psychology, 26(5): 629-638. DOI:10.1080/09515089.2012.696327.

Tobia, Kevin P., Gretchen Chapman, and Stephen Stich. 2013. "Cleanliness is Next to Morality, Even for Philosophers." Journal of Consciousness Studies, 20 (11 and 12): 195204.

Tobia, Kevin P., and Stephen Stich. Manuscript. "A Big and Bold Argument About Expert Intuition."

Turri, John. 2013. “A Conspicuous Art: Putting Gettier to the Test." Philosophers' Imprint, 13(10): $1-16$. 
Vaesen, Krist, Martin Peterson, and Bart Van Bezooijen. 2013. "The Reliability of Armchair Intuitions." Metaphilosophy, 44(5): 559-578. DOI:10.1111/meta.12060.

Weinberg, Jonathan, Shaun Nichols, and Stephen Stich. 2001. "Normativity and Epistemic Intuitions." Philosophical Topics, 29(1-2): 429-460.

DOI:10.5840/philtopics2001291/217.

Weinberg, Jonathan. 2014. "Cappelen between a Rock and a Hard Place." Philosophical Studies, 171(3): 545-553. DOI:10.1007/s11098-014-0286-z.

Williamson, Timothy. 2004. "Philosophical 'Intuitions' and Skepticism About Judgment." Dialectica, 58(1): 109-153.

Williamson, Timothy. 2005. "Armchair Philosophy, Metaphysical Modality and Counterfactual Thinking." Proceedings of the Aristotelian Society, 105: 1-23.

Williamson, Timothy. 2007. The Philosophy of Philosophy, Oxford: Blackwell Publishing.

Williamson, Timothy. Forthcoming. "Review of Joshua Alexander, Experimental Philosophy." Philosophy.

${ }^{1}$ Perhaps it would be better to say "largely uncontroversial examples," since in philosophy almost nothing is uncontroversial. In a recent book, Cappelen (2012) maintains that while many philosophers believe they use intuitions as an important source of evidence, they are mistaken about their own practice. We'll return to Cappelen's provocative view at the end of this section. The strategy of beginning with (largely) uncontroversial examples is endorsed by Anna-Sara Malmgren in her insightful review of Cappelen's book (Malmgren 2013).

${ }^{2}$ For more detailed discussions of the use of intuitions in philosophy, see Pust (2000), Ch. 1, and Alexander (2012), Ch.1.

3 There is a growing consensus that Cappelen's attempt to show that philosophers don't really use intuitions as evidence is undermined by his implausibly restrictive characterization of intuitions. See, for example, Chalmers (2014), Malmgren (2013), and Weinberg (2014).

${ }^{4}$ Two important caveats are in order here. First, some experimental philosophers fall in both clusters, since they are motivated by the positive program when studying some intuitions, and by the negative program (discussed below) when studying other intuitions. Second, as Sytsma and Machery (2013) and Sytsma and Livengood (forthcoming) have noted, there is a substantial body of work in experimental philosophy that is not motivated by either program. Those engaged in this work "are interested in intuitions for their own sake, finding them to be a worthy topic of philosophical investigation" (Sytsma and Livengood, Forthcoming, §3.4).

${ }^{5}$ Goldman (2010, §9) notes that similar views are defended by Chalmers and Jackson (2001) and Ludwig (2007).

6 Jaakko Hintikka (1999) maintains that the term "intuition" was rarely used in $20^{\text {th }}$ century analytic philosophy until Chomsky and his followers popularized its use in linguistics. Andow (forthcoming) offers quantitative evidence that there was a dramatic increase in the use of the term in philosophy starting about 1970.

7 The term "positive program," and the term "negative program," which we'll encounter shortly, are widely used, though their provenance is unclear. 
${ }^{8} \mathrm{An}$ alternative hypothesis is that the side-effect effect is itself a performance error, and that the intuitions of participants in these experiments do not tell us what their concept of intentional action actually says about some of these cases. See Alexander, Mallon, and Weinberg (2010) for a discussion of some of the problems encountered in the attempt to decide between these hypotheses.

${ }^{9}$ A pair of papers by Eddy Nahmias and his colleagues (Nahmias et al., 2005, 2006) provides another important example of the positive program. In the literature on free will, a number of philosophers report strongly incompatibilist intuitions - i.e. intuitions indicating that free will cannot exist in a determinist universe. However, Nahmias and colleagues have shown that non-philosophers tend to have compatibilist intuitions - intuitions indicating that free will can exist in a determinist universe. This suggests that the incompatibilist intuitions of many philosophers may be theoretically driven performance errors of the sort that Goldman warned against.

${ }^{10}$ In his paper in this volume, Knobe argues that for the last five years most of the empirical research in experimental philosophy has not been concerned with the analysis of philosophically important concepts, or with the sort of critique of philosophical methodology that will be center stage in §3.2. Rather, he maintains, "the vast majority of [recent] research is cognitive science. It consists of identifying surprising effects in people's intuitions and explaining those effects in terms of underlying cognitive processes" (Knobe, this volume, $\S \mathrm{VIII}$ ). The lesson he draws from this is that "experimental philosophy is pursuing philosophical questions in a way that is genuinely new" (Ibid). This is not the place to debate Knobe's account of recent work in experimental philosophy. But if his portrait is accurate, it invites an obvious challenge: Why is this work philosophy? Knobe's contention that it is pursuing philosophical questions in a genuinely new way is not likely to satisfy those who pose this challenge, since he has not told us what these questions are, or why they should be viewed as philosophical questions.

11 For a particularly trenchant critique of this assumption, see Goldman $(2007,7)$.

12 See, for example, Stich 1988 and 1990.

${ }^{13}$ For details, see Machery et al. (under review).

${ }^{14}$ Liao et al. (2012) found people's intuitions about trolley problems were affected by the order of the cases' presentation. Helzer and Pizarro (2011) found that people's moral intuitions differed when they were in the presence of a hand-sanitizer. Schnall et al. (2008) report that certain smells affected moral intuitions. We will discuss an example of a wording effect in $\S 4$. 